\title{
Developing and producing a focused conference poster
}

Sally Dowling and John Albarran

Sally Dowling, Senior Lecturer, Adult Nursing

John Albarran, Associate Professor for Critical \& Cardiovascular Nursing

Centre for Health and Clinical Research, Faculty of Health and Applied Sciences, University of the West of England, Bristol, BS16 1DD 


\begin{abstract}
This fourth article in the writing for publication series aims to provide guidance on developing and producing a poster presentation for a conference. Most academic conferences offer the opportunity for healthcare professionals to present their work as either an oral presentation or a poster; an earlier paper in this series discussed the submission of abstracts to conference organisers for consideration. Planning, preparing and producing a poster presentation requires different skills to those used when giving an oral presentation. These are discussed in this paper by outlining what is meant by a poster presentation, discussing key issues to consider when planning and producing your poster and when taking it to, and presenting at, your chosen conference.
\end{abstract}

Terms: poster presentation; poster preparation; poster skills 


\section{Introduction}

Information about research is disseminated in a range of formats; the poster is one requiring different skills to those used in oral presentations or when writing for publication (Briggs, 2009). When submitting an abstract to conference organisers you may be asked to indicate whether your preference is for poster or oral presentation (Albarran and Dowling, 2017); sometimes if you are unsuccessful in gaining a place to present your work orally you may instead be offered the opportunity to bring a poster. For this and other reasons, posters can sometimes be perceived as 'second best' and less prestigious (Briggs, 2009): however, whether it was your original choice or not, posters allow you to organise your thinking, succinctly explain your work to others and to disseminate it to a wide audience. In this paper, we begin by outlining what is meant by a poster presentation and review some of the advantages of presenting your work in this way. This is followed by a discussion of key issues to consider when planning and producing your poster, and then taking it to, and presenting it at, your chosen conference.

\section{What is a poster presentation?}

A poster presentation at a conference is a way of creating a visual representation of your work, and of having an opportunity to share and discuss it face-to-face with conference participants (Beins and Beins, 2012). Taking a poster presentation to a conference offers the opportunity to showcase a range of academic and clinical work. This could be the results of your research study, the findings from a service evaluation or improvement project, or the results of an audit or other work in your clinical setting. You may also present work in progress; whatever your focus, the conference poster is a good opportunity to disseminate your ideas and engage with fellow professionals.

Other advantages of posters include reaching large audiences, enhancing reputation and morale boosting (Briggs, 2009). The poster can also be the first step in working on your ideas, prior to producing an article for publication (Wood and Morrison, 2011). It's an opportunity, which nurse researchers may particularly value, to exchange information and network with others in the profession (Hand, 2010). If you are a novice presenter it can give you the opportunity to practice organising your ideas succinctly as well as being able to 
discuss them with individual conference participants, rather than having stand up and talk to a large room full of people, which can be daunting.

Obtaining key information before you start

Most conferences organisers will provided detailed and specific guidelines relating to size of poster, whether landscape or poster format and how this can be affixed. There may be some suggestions around headings and font size, but the content will be left with authors. Make sure that you are familiar with these before you start producing your poster, as well as when you take it to the conference. Guidelines relating to the poster production and what might happen at the conference could include the information shown in Table 1. If there is anything you are unsure about, email the conference organisers. It is better to check before you have sent your poster to the printers!

What is the aim of your poster?

The aim of your poster should have been clearly expressed in your accepted abstract. However, you still might want to think about this in more detail before you start to plan the content. Are you presenting an entire research project or just an element of one? For instance, are you aiming to highlight a specific aspect of your work such as the findings, or methodological innovation? Is there a clinical development or new practice that you want to bring to delegates' attention? How you develop the poster can be a way of drawing in delegates, refering them to published work elsewhere and creating opportunities for further interaction to build networks. It is important, however, that your aim is clear - and that the poster stands alone in telling a story, even if that is part of a greater whole. Many conferences will include posters as part of a competition. Members of the scientific committee or delegates will judge the quality and contribution of your work in terms of clarity, organisation and originality and select the best one for a prize. Spending time at the outset is a worthwhile investment.

Designing your poster

When your poster is displayed - maybe amongst many others - you want it to stand out and be visually appealing; this may be just as important as the content (Wood and Morrison, 2011). A conference delegate may only look for a few seconds before deciding whether to 
move on or stay and learn more. Designing your poster is important and worth spending time on; of course, the content matters too but how you present it will be how you attract people to read your poster - and affects how much of the information you offer they are able to read and retain. Allow plenty of time for planning and designing your poster, allowing for revisions and edits (Pontin and Albarran, 2009; Hand, 2010).

Presenting your information by breaking it up into in columns of text allows people to read it more easily and for more than one person to read it at once. Understanding how people behave when reading text can also help you in designing your poster - most people will read from top to bottom and from left to right (University of Liverpool, 2012). Think about the information and ideas you are conveying and how best to do this.

Use a range of different tools - such as photographs, diagrams, text boxes - to create a visually interesting and professional looking product. It's important that the reader can follow the 'story' that you are telling them; make this easier by using headings (related to your abstract if relevant) or other visual cues such as arrows or other ways of indicating 'flow'. Leave some space and don't feel that you must fill it all with information.

If you are including photographs (which can help to break up the text), make sure that you have got permission and that you are not using copyright images, or images of research participants without consent. Use colour carefully so that your poster is not confusing, and think about why and where it is appropriate. A strong image can convey and express ideas visually, so use this appropriately to enhance and complement the text.

It may not be specified by the conference organisers but your poster will look much more professional if you design it to be expertly printed rather than produce it by hand. Equally, posters that are printed on one large page tend to appear as more professional than those constructed from many A4 sheets stuck next to each other on a poster board. There are different ways to produce a poster but one effective way is to use Microsoft Powerpoint; other software is also used, you may have to try a range to find what works best for you and your ideas. Using Powerpoint, you can design your poster with both images and text on a single slide, which you can then set to the size of your final poster; this will also help you in assessing whether you have chosen the right font. A well designed conference poster must be able to be read clearly from about one to two metres away (University of Liverpool, 
2012). Too much text, which is too small, will put people off or mean that one person must stand very close to the poster and prevent other delegates from viewing it at the same time. Therefore, give careful consideration to font size, likewise give attention to the font type as some are easier to read than others.

\section{What do you need to include?}

If you are presenting the results of a study it would be usual to use the standard headings (background, aim, method, results, discussion - or similar) but your work might not fit with this structure. Visitors to your poster will have seen the abstract you submitted (and this may be why they have sought out your poster) so it's important that the content reflects this as much as possible, and is in a similar order. Think about the main message you want to get across and then make sure that the different parts of the poster are working together to convey this (Singh, 2014). Too much text is off-putting so you need to really work at being succinct, whatever type of project you are presenting. Think about your audience (are they specialists or generalists? Professionals or patient/user representatives - or both?) and relay the information accordingly, for example appropriately pitching statistical information (Briggs, 2009).

There are other pieces of important information that you must not forget to include. The title of your poster will usually be the same as the one in your abstract and so should give the viewer enough information about what the poster will contain. An earlier paper in this series outlined the important features of the abstract title (Albarran and Dowling, 2017); these also apply to the poster title. Institutional logos should be included if required (remembering everyone who was involved) and the names of all authors, with their affiliations included. Don't forget to acknowledge anyone else whose contribution was important and include ethical approval information if appropriate. Table 2 can be used to remind you about other factors to remember when planning your poster.

This might seem like a lot to remember, and to include, but despite this it is important to only include what is essential - it is tempting to cram in as much information as possible, but this may fail to engage delegates. Don't include anything that isn't related to the work you are presenting and to the message you want to get across. If you can look at other 
posters before you produce yours this may help - think about which ones work best and try and work out why; this can be very helpful when planning and designing your own poster.

\section{Printing your poster}

Best results will be achieved by having your poster professionally printed. This is not too expensive and the costs may be covered by your employer (you may have a department in your workplace that can do this printing for you). Posters are usually printed and then laminated, ready to be rolled for transportation. Some suppliers now offer fabric printing, resulting in a finished poster that can be folded with minimal creasing. Make sure you allow plenty of time for printing and that you very carefully check your text and layout before giving or sending it to the printers.

How will you get your poster to the conference?

Posters can be quite large and unwieldy, particularly if the required size is A1. Even A2 posters can be difficult to transport. If you must travel far, or if air travel is involved, you may want to consider fabric printing, as above. If you opt for traditional printing you will need a rigid cardboard tube in which to transport your poster - these can be quite awkward to carry on and off public transport. If you are travelling by air you should check the baggage restrictions in advance; sometimes it may be possible to send your poster to the conference ahead of the time that you will travel.

What will happen when you are at the conference?

Many conferences now schedule time in their programmes for poster presenters to stand next to their posters and be available to answer questions about their work, sometimes called a 'poster walk' or 'poster session'. The organisers will usually tell you in advance when these are and, if there is more than one, if you are expected to be at them all. It is a good idea to take some A4 sheets with you, summarising your project and giving your contact details - you can give these to interested conference attendees who might want to later contact you for further information. Remember that most people won't look at the poster for very long (see Table 3). Hand (2010) has written a useful reflection on her experiences of producing a poster for a Royal College of Nursing (RCN) conference; her final 
point is one worth remembering 'The poster cannot present all the information - it is the presenter who brings it to life' (Hand, 2010: 59).

\section{Conclusion}

Posters are increasingly used at academic and professional conferences; they are an opportunity to disseminate your work and engage with others in your field and beyond. To produce an interesting and professional poster there are a number of factors to consider, and careful planning is required. Taking time to think about the message you want to convey and working on the most visually interesting way of doing this is crucial to engaging other delegates with your work. Taking a poster to a conference can be a good way for novice presenters to gain experience and skills in thinking about how to explain their work to others; these can then be further developed by susbseqently engaging in writing to submit for publication, or through future oral presentations.

\section{References}

Albarran, J. and Dowling, S. (2017) Writing an effective conference abstract, British Journal of Cardiac Nursing, 12(7): 274-277.

Beins, B.C. and Beins, A.M. (2012) Effective Writing in Psychology: Papers, Posters, and Presentations, $\left(2^{\text {nd }}\right.$ Ed). John Wiley \& Sons, Inc.

Briggs, D.J. (2009) A practical guide to designing a poster for presentation, Nursing Standard, 23(34): 35-39.

Hand, H. (2010) Reflections on preparing a poster for an RCN conference. Nurse Researcher, 17(2): 52-59.

Pontin, D. and Albarran, J. (2009) Preparing a conference poster, British Journal of Cardiac Nursing, 3(3): 117-120.

Singh, M.K. (2014) Preparing and presenting effective abstracts and posters in psychiatry, Academic Psychiatry 38:709-715.

University of Liverpool (2012) Making an impact with your poster (Online). Available from: https://www.liverpool.ac.uk/media/livacuk/computingservices/printing/making-an-impactwith-your-poster.pdf

Wood, G.J. and Morrison, R.S. (2011) Writing Abstracts and Developing Posters for National Meetings, Journal of Palliative Medicine, 14(3): 353-359. 
Table 1: What do I need to know about preparing my poster?

\begin{tabular}{|l|l|}
\hline \multicolumn{1}{|c|}{$\begin{array}{c}\text { Information relating to the poster } \\
\text { production }\end{array}$} & $\begin{array}{c}\text { Information relating to displaying the } \\
\text { poster at the conference }\end{array}$ \\
\hline $\begin{array}{l}\text { What size do the conference organisers } \\
\text { want the poster to be? (A2 or A1 are } \\
\text { common). }\end{array}$ & $\begin{array}{l}\text { Where and when do I take my poster (this } \\
\text { might be during the registration period or } \\
\text { could be during the first day). }\end{array}$ \\
\hline $\begin{array}{l}\text { Does the orientation of the poster } \\
\text { matter? (the organisers may not } \\
\text { specify, or they may prefer them all to } \\
\text { be landscape or all portrait). }\end{array}$ & $\begin{array}{l}\text { Do I need to put my poster up in position } \\
\text { myself? Will fixings will be available? (it is } \\
\text { perhaps advisable to take spares in any } \\
\text { case). }\end{array}$ \\
\hline $\begin{array}{l}\text { Is there any information that I must put } \\
\text { on my poster? (name, contact details } \\
\text { etc). }\end{array}$ & $\begin{array}{l}\text { What are the timings of any 'poster } \\
\text { walks' and what are the requirements for } \\
\text { me to be with my poster? }\end{array}$ \\
\hline
\end{tabular}


Table 2: Important factors to remember when planning your poster

Is the title the same as on the submitted abstract?

Is there a logical flow to the text, indicated by headings (background, aim, method, results, discussion, etc.)?

Have you used photographs or images to add interest (directly related to the content)?

Have you considered use of colour to break up the text?

Are all authors names and affilliations included?

Have you included all relevant logos, including the funder, if appropriate?

Are the contact details for the first author, for further information, clearly on the poster? 
Table 3: The 'rule of 10's'

'It is helpful to remember the rule of 10s: the average person scans your poster for 10 seconds from 10 feet away. When someone stops, you should be able to introduce your poster in 10 seconds and they should be able to assimilate all of the information and discuss it with you in 10 minutes' (Wood and Morrison, 2011:357). 